\title{
In vivo and Postmortem Clinicoanatomical Correlations in Frontotemporal Dementia and Parkinsonism Linked to Chromosome 17
}

\author{
Bernardino Ghetti ${ }^{a} \quad$ Salvatore Spina ${ }^{a}$ b Jill R. Murrella Edward D. Huey ${ }^{c}$ \\ Pietro Pietrini ${ }^{c, d}$ Brian Sweeney ${ }^{\mathrm{e}}$ Eric M. Wassermann ${ }^{c}$ Catherine Keohane ${ }^{\mathrm{e}}$ \\ Martin R. Farlow ${ }^{a} \quad$ Jordan Grafman ${ }^{c}$ \\ a Indiana Alzheimer Disease Center, Indiana University School of Medicine, Indianapolis, Ind., USA; \\ ${ }^{b}$ Department of Neurological and Behavioral Sciences, University of Siena, Siena, Italy; ${ }^{c}$ Cognitive Neuroscience \\ Section, National Institute of Neurological Disorders and Stroke, National Institute of Health, Bethesda, Md., USA;

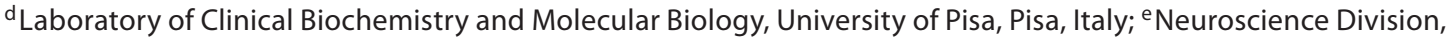 \\ Cork University Hospital, Wilton, Cork, Ireland
}

\section{Key Words}

Frontotemporal dementia and parkinsonism linked

to chromosome $17 \cdot$ Tau • Ubiquitin - TDP-43 •

Neuropathology

\begin{abstract}
Background: Frontotemporal dementia and parkinsonism linked to chromosome 17 (FTDP-17) is associated with mutations in the Microtubule-Associated Protein Tau (MAPT) gene or the Progranulin (PGRN) gene. MAPT mutations lead to widespread deposition of hyperphosphorylated tau protein (FTDP-17T). PGRN mutations are associated with ubiquitinand TDP-43-positive inclusions in the frontotemporal cortex, striatum and hippocampus (FTDP-17U). Despite the differences, FTDP-17T and FTDP-17U share a largely overlapping clinical phenotype. Objective: To determine whether neuroimaging studies may allow an in vivo early differentiation between FTDP-17T and FTDP-17U. Methods: We studied 25 individuals affected with FTDP-17T associated with either the exon $10+3$ (24 subjects) or the G335S (1 subject) MAPT mutation, as well as 3 FTDP-17U individuals, who were carriers of the A9D, IVS6-2A >G or R493X PGRN mutation. Neuro-
\end{abstract}

imaging studies, obtained along the course of the disease, were compared to the neuropathologic findings. Results: FTDP-17T cases were associated with symmetric frontotemporal atrophy. Behavioral changes constituted the predominant clinical presentation. Conversely, an asymmetric degenerative process was seen in all 3 PGRN cases, who presented with either corticobasal syndrome (A9D) or frontotemporal dementia and language deterioration (IVS6$2 A>G$ and R493X). Conclusion: Neuroimaging data, in the early disease stage of FTDP-17, may offer the possibility of an early differentiation of FTDP-17T and FTDP-17U phenotypes, independent of the genetic analysis.

Copyright $\odot 2008$ S. Karger AG, Basel

Mutations in either the Microtubule-Associated Protein Tau (MAPT) gene or the Progranulin (PGRN) gene are associated with frontotemporal dementia and parkinsonism linked to chromosome 17 (FTDP-17) [1-3]. Clinically, FTDP-17 is characterized by a variable combination of behavioral changes, executive dysfunction, language impairment and parkinsonism [4]. Pathologically, MAPT mutations are invariably associated with wide-

\section{KARGER}

๑ 2008 S. Karger AG, Basel

Fax +4161306 1234

E-Mail karger@karger.ch

www.karger.com
Accessible online at:

www.karger.com/ndd
Bernardino Ghetti, MD

Indiana Alzheimer Disease Center, Department of Pathology and Laboratory Medicine Indiana University School of Medicine, Medical Science Building A138 635 Barnhill Drive, Indianapolis, IN 46202 (USA)

Tel. +1 317274 7818, Fax +1 317274 4882, E-Mail bghetti@iupui.edu 
spread deposition of hyperphosphorylated tau protein in the central nervous system of affected individuals (FTDP17T) [5]. On the contrary, the neuropathology of cases with $P G R N$ mutations is characterized by the presence of tau-negative, ubiquitin- and TDP-43-positive neuronal and glial inclusions in the frontotemporal cortex and subcortical white matter, striatum and dentate gyrus of affected individuals (FTDP-17U) [6]. In spite of these differences, FTDP-17T and FTDP-17U share a largely overlapping range of clinical presentations that limits the possibility of antemortem differential diagnosis between the two syndromes to the genetic analysis only. Here we review clinical, neuroimaging and neuropathological findings obtained from a subset of FTDP-17 patients. Neuroimaging data are considered in order to evaluate the hypothesis that phenotypic differences may allow an in vivo early differentiation between the FTDP-17T and FTDP$17 \mathrm{U}$ syndromes, prior to genetic or postmortem investigation.

\section{Materials and Methods}

We have reviewed clinical and, when available, imaging and neuropathological data from 28 individuals affected with FTDP17: 24 carriers of the exon $10+3$ MAPT mutation, 1 carrier of the G335S MAPT mutation, and 3 carriers of distinct PGRN mutations (A9D, IVS6-2A $>$ G and R493X). MRI scans were available for 8 exon $10+3$ MAPT mutation carriers, the carrier of the G335S MAPT mutation and the 3 PGRN mutation carriers. PGRN mutation carriers also underwent PET scan. Histology and immunohistochemistry (phosphorylated tau, ubiquitin, and TDP43) were carried out in 14 exon 10+3 MAPT mutation carriers, the G335S $M A P T$ mutation carrier and the $3 P G R N$ mutation carriers.

\section{Results}

Among individuals with the exon $10+3$ MAPT mutation for whom this information was available, $81 \%$ presented with behavioral, personality and executive changes; $14 \%$ had parkinsonism as early major complaint, and $5 \%$ presented with isolated memory loss. Neuroimaging disclosed predominant frontotemporal atrophy, with a symmetric pattern in virtually all cases. Neuropathological examination revealed findings consistent with the diagnosis of 'multiple system tauopathy with presenile dementia' [7]. The carrier of the G335S MAPT mutation presented with social withdrawal and personality changes at age 22. Later on in the disease course, he developed dysexecutive symptoms, parkinsonism and ideomotor apraxia. Neuroimaging examination in vivo and post- mortem neuropathological examination revealed severe atrophy of the frontal and temporal lobes, in a symmetric fashion. Abundant neuronal and glial tau pathology was observed with tau immunohistochemistry. Frontotemporal dementia and progressive nonfluent aphasia characterized the clinical presentation of the 2 individuals harboring the IVS6-2A $>$ G or the R493X PGRN mutations. On the contrary, the third $P G R N$ mutation carrier (A9D) presented with corticobasal syndrome with features of left-sided hemineglect and alien-hand syndrome. Interestingly, an asymmetric degenerative process was observed in all 3 PGRN mutation carriers both at neuroimaging and neuropathological examination. Predominant atrophy and hypometabolism in the left cerebral hemisphere was observed in the IVS6-2A $>$ G and R493X $P G R N$ mutation carriers. Mirrored findings were observed in the A9D PGRN mutation carrier, who displayed predominant atrophy and hypometabolism of the right cerebral hemisphere. Cases with $P G R N$ mutation matched pathological criteria for 'frontotemporal lobar degeneration with ubiquitin- and TDP-43-positive inclusions' and displayed neuronal intranuclear inclusions [6]. Additional information on these cases is provided elsewhere [8-11].

\section{Discussion}

This review of FTDP-17 cases suggests the possibility of a different pattern of involvement of the cerebral hemispheres in the FTDP-17T and FTDP-17U cases. While virtually all subjects with FTDP-17T presented a symmetric pattern of frontotemporal lobar degeneration both at neuroimaging and neuropathological examination, all of the FTDP-17U cases were characterized by a striking lateralization of the degenerative process, with significantly severer involvement of one cerebral hemisphere compared to the contralateral one. The higher degree of asymmetry characterizing the degenerative process of the cerebrum in FTDP-17U cases may constitute the anatomopathologic base for the identification of more topographically restricted patterns of cognitive dysfunction in FTDP-17U cases compared to what is observed in FTDP-17T cases. Specifically, a severer degree of atrophy of the dominant hemisphere may have led to a more clinically significant impairment of language in the early disease course of the subjects with the IVS6-2A $>G$ and R493X PGRN mutations. A severer involvement of the nondominant hemisphere may have resulted in the clinical observation of signs, such as contralateral hemine- 
glect or alien-hand syndrome observed in the carrier of the A9D PGRN mutation [10]. These data are consistent with those of several reports of FTDP-17 associated with $P G R N$ mutation [12-15]. In one of these studies, the authors emphasize the contrast between the markedly asymmetric distribution of pathological changes in a carrier of the Q486X PGRN mutation and the relatively symmetric atrophic process observed in a series of FTDP-17T individuals, carriers of the exon 10+16 MAPT mutation [13]. Although these data are not based on the study of a large series of cases, they raise the possibility that an asymmetric involvement of the cerebrum might consti- tute a more likely event in FTDP-17U than in FTDP-17T. This multidisciplinary approach provides valuable insights into the natural history of these disorders and tests the possibility of an early clinical differentiation of FTDP17T and FTDP-17U phenotypes, independent of the genetic investigation.

\section{Acknowledgment}

This study was supported by PHS AG10133, NINDS Intramural Program and Department of Neurological and Behavioral Sciences, University of Siena, Siena, Italy.

\section{References}

-1 Baker M, Mackenzie IR, Pickering-Brown SM, Gass J, Rademakers R, Lindholm C, Snowden J, Adamson J, Sadovnick AD, Rollinson S, Cannon A, Dwosh E, Neary D, Melquist S, Richardson A, Dickson D, Berger Z, Eriksen J, Robinson T, Zehr C, Dickey CA, Crook R, McGowan E, Mann D, Boeve B, Feldman H, Hutton M: Mutations in progranulin cause tau-negative frontotemporal dementia linked to chromosome 17. Nature 2006;442:916-919.

$>2$ Cruts M, Gijselinck I, van der Zee J, Engelborghs S, Wils H, Pirici D, Rademakers R, Vandenberghe R, Dermaut B, Martin JJ, van Duijn C, Peeters K, Sciot R, Santens P, De Pooter T, Mattheijssens M, Van den Broeck M, Cuijt I, Vennekens K, De Deyn PP, Kumar-Singh S, Van Broeckhoven C: Null mutations in progranulin cause ubiquitin-positive frontotemporal dementia linked to chromosome 17q21. Nature 2006;442:920924.

$>3$ Hutton M, Lendon CL, Rizzu P, Baker M, Froelich S, Houlden H, Pickering-Brown S, Chakraverty S, Isaacs A, Grover A, Hackett J, Adamson J, Lincoln S, Dickson D, Davies P, Petersen RC, Stevens M, de GraaffE, Wauters E, van Baren J, Hillebrand M, Joosse M, Kwon JM, Nowotny P, Che LK, Norton J, Morris JC, Reed LA, Trojanowski J, Basun H, Lannfelt L, Neystat M, Fahn S, Dark F, Tannenberg T, Dodd PR, Hayward N, Kwok JB, Schofield PR, Andreadis A, Snowden J, Craufurd D, Neary D, Owen F, Oostra BA, Hardy J, Goate A, van Swieten J, Mann D, Lynch T, Heutink P: Association of missense and $5^{\prime}$-splice-site mutations in tau with the inherited dementia FTDP-17. Nature 1998;393:702-705.
4 Foster NL, Wilhelmsen K, Sima AA, Jones MZ, D’Amato CJ, Gilman S: Frontotemporal dementia and parkinsonism linked to chromosome 17: a consensus conference. Ann Neurol 1997;41:706-715.

5 van Swieten J, Spillantini MG: Hereditary frontotemporal dementia caused by Tau gene mutations. Brain Pathol 2007; 17:63-73.

-6 Cairns NJ, Bigio EH, Mackenzie IR, Neumann M, Lee VM, Hatanpaa KJ, White CL 3rd, Schneider JA, Grinberg LT, Halliday G, Duyckaerts C, Lowe JS, Holm IE, Tolnay M, Okamoto K, Yokoo H, Murayama S, Woulfe J, Munoz DG, Dickson DW, Ince PG, Trojanowski JQ, Mann DM: Neuropathologic diagnostic and nosologic criteria for frontotemporal lobar degeneration: consensus of the Consortium for Frontotemporal Lobar Degeneration. Acta Neuropathol (Berl) 2007; 114:5-22.

7 Spillantini MG, Goedert M, Crowther RA, Murrell JR, Farlow MR, Ghetti B: Familial multiple system tauopathy with presenile dementia: a disease with abundant neuronal and glial tau filaments. Proc Natl Acad Sci USA 1997;94:4113-4118.

8 Spina S, Murrell JR, Huey ED, Wassermann EM, Pietrini P, Baraibar MA, Barbeito AG, Troncoso JC, Vidal R, Ghetti B, Grafman J: Clinicopathologic features of frontotemporal dementia with progranulin sequence variation. Neurology 2007;68:820-827.

9 Spina S, Murrell JR, Yoshida H, Ghetti B, Bermingham N, Sweeney B, Dlouhy SR, Crowther RA, Goedert M, Keohane C: The novel Tau mutation G335S: clinical, neuropathological and molecular characterization. Acta Neuropathol (Berl) 2007;113:461470 .
10 Spina S, Murrell JR, Huey ED, Wassermann EM, Pietrini P, Grafman J, Ghetti B: Corticobasal syndrome associated with the A9D Progranulin mutation. J Neuropathol Exp Neurol 2007;66:892-900.

11 Spina S, Farlow MR, Unverzagt FW, Kareken DA, Murrell JR, Fraser G, Epperson F, Crowther RA, Spillantini MG, Goedert M, Ghetti B: The tauopathy associated with mutation +3 in intron 10 of Tau: characterization of the MSTD family. Brain 2008;131: 72-89.

12 Benussi L, Binetti G, Sina E, Gigola L, Bettecken T, Meitinger T, Ghidoni R: A novel deletion in progranulin gene is associated with FTDP-17 and CBS. Neurobiol Aging 2006, E-pub ahead of print.

13 Snowden JS, Pickering-Brown SM, Mackenzie IM, Richardson AMT, Varma A, Neary D, Mann DMA: Progranulin gene mutations associated with frontotemporal dementia and progressive non-fluent aphasia. Brain 2006;129:3091-3102.

14 Masellis M, Momeni P, Meschino W, Heffner R, Elder J, Sato C, Liang Y, St GeorgeHyslop P, Hardy J, Bilbao J, Black S, Rogaeva E: Novel splicing mutation in the progranulin gene causing familial corticobasal syndrome. Brain 2006;129:3115-3123

15 Mesulam M, Johnson N, Krefft TA, Gass JM, Cannon AD, Adamson JL, Bigio EH, Weintraub S, Dickson DW, Hutton ML, GraffRadford NR: Progranulin mutations in primary progressive aphasia: the PPA1 and PPA3 families. Arch Neurol 2007;64:43-47. 